\title{
PENGARUH POLA ASUH ORANG TUA DENGAN PENDEKATAN REGULASI DIRI TERHADAP HASIL BELAJAR SISWA PADA MATA PELAJARAN IPS TERPADU SISWA SMP
}

\author{
${ }^{1}$ Titah Anugrah Gusti, ${ }^{2}$ Risma Dwi Arisona \\ ${ }^{1}$ Institut Agama Islam Negeri Ponorogo \\ titahanugerah@gmail.com \\ ${ }^{2}$ Institut Agama Islam Negeri Ponorogo \\ arisona@iainponorogo.ac.id \\ ABSTRAK
}

\begin{abstract}
Banyak orang tua dari siswa tidak mendapingi siswa dalam belajar, karena banyak dari para orang tua sibuk bekerja di dalam dan luar negeri (TKI). Padahal yang diperlukan seorang anak ialah perhatian, dorongan, motivasi dan bimbingan dari orang tua, guru maupun hal tersebut bisa saja mucul di dalam dirinya sendiri. Hal tersebut mengakibatkan hasil belajar siswa menjadi kurang maksimal. Tujuan penelitian ini untuk mengetahui pengaruh pola asuh orang tua dengan pendekatan regulasi diri terhadap hasil belajar siswa pada mata pelajaran IPS Terpadu siswa SMP. Dalam penelitian ini peneliti mengunakan pendekatan kuantitatif. Sampel yang digunakan berjumlah 61 siswa. Data dikumpulkan menggunakan angket sebagai instrument dari variabel pola asuh orangtua dan regulasi diri, sedangkan hasil belajar diambil dari ujian akhir semester. Hasil dari angket dibantu dengan SPSS for windows versi 25 . Hasil analisis data menunjukkan bahwa terdapat pengaruh yang signifikan antara pola asuh orangtua dengan pendekatan regulasi diri, terdapat pengaruh yang signifikan antara pendekatan regulsi diri terhadap hasil belajar IPS siswa, variabel regulasi diri memperkuat pengaruh langsung pola asuh orangtua terhadap hasil belajar IPS siswa sebesar $25 \%$.
\end{abstract}

Kata Kunci: Pola Asuh Orang Tua, Regulasi Diri, Hasil Belajar

\section{ABSTRACT}

Many parents of students do not accompany students in studying, because many of the parents are busy working at home and abroad (TKI). Whereas what a child needs is attention, encouragement, motivation and guidance from parents, teachers or this may appear within himself. This results in student learning outcomes being less than optimal. The purpose of this study was to determine the effect of parenting style with a selfregulation approach on the learning outcomes of the VII grade students of SMP Negeri 1 Balong. In this study, researchers used a quantitative approach. The sample used was 63 students. Data were collected using a questionnaire as an instrument of parenting style variables and self-regulation, while learning outcomes were taken from the final semester exams. The results of the questionnaire were assisted by SPSS for windows version 25 . The results of the data analysis showed that there was a significant influence between parenting styles and the self-regulation approach, there was a significant influence between the selfregulation approach on student social studies learning outcomes, the self-regulation variable strengthened the direct effect of the pattern. Parental care for student social studies learning outcomes by $25 \%$.

Keywords: Parenting Style, Self Regulation, Learning Outcomes 


\section{PENDAHULUAN}

Masa remaja merupakan masa peralihan dari usia anak-anak menuju masa dewasa. Pada masa peralihan tersebut memungkinkan terjadinya masa konfrontasi ditandai dengan kecenderungan munculnya perilaku menyimpang. Dengan demikian peran orang tua sangat dibutuhkan agar tidak semakin banyak remaja yang terjerumus kedalam perilaku yang tidak sesuai dengan nilai dan norma yang ada dalam masyarakat. ${ }^{1}$

Pola asuh yang baik dan sikap positif lingkungan serta penerimaan masyarakat terhadap keberadaan anak akan menumbuhkan konsep diri positif bagi anak dalam menilai diri sendiri. Anak menilai dirinya berdasarkan apa yang dialami dan dapatkan dari lingkungan. Jika lingkungan masyrakat memberikan sikap yang baik dan positif dan tidak memberikan label atau cap yang negatif pada anak, maka anak akan merasa dirinya cukup berharga sehingga tumbuhlah diri yang positif. ${ }^{2}$

Pola asuh ada tiga, yaitu pola asuh otoriter, pola asuh demokratis dan pola asuh permisif. ${ }^{3}$ Pola asuh yang paling tepat digunakan adalah pola asuh yang disesuaikan dengan keadaan anak dan harus sesuai kebutuhan. Apabila berkenaan dengan masalah ibadah, maka akan lebih baik pola asuh otoriter yang dipakai oleh orang tua. Namun dalam masalah lain pola asuh demokratis lebih tepat untuk digunakan dan tetap dalam pengawasan orang tua agar anak tidak merasa terkekang dan mampu menemukan jati dirinya. Sesekali pola asuh permisif dibutuhkan saat anak sudah mampu mengendalikan diri dengan baik dan mampu bertanggung jawab atas apa yang dilakukan agar anak mampu hidup mandiri dan menentukan jalannya sendiri sesui keinginannya. Hal tersebut akan membuat anak berfikir bahwa orang tuanya tidak semena-mena dalam menentukan jalan hidupnya dan mau memahaminya dengan baik, sehingga anak akan jauh dari hal-hal buruk.

Regulasi diri merupakan kemampuan untuk mengatur tingkah laku dan menjalankan tingkah laku sebagai strategi yang berpengaruh terhadap performasi seseorang mencapai tujuan atau prestasi sebagai bukti peningkatan. ${ }^{4}$ Regulasi diri merujuk pada pikiran, perasaan dan tindakan yang terencana oleh diri dan secara siklus disesuaikan dengan usaha

Menurut Alsa, teori belajar sosial kognitif sudah menjelaskan konsep ideal pembelajar yaitu pembelajar berdasar regulasi diri. Istilah belajar berdasar regulasi diri merupakan terjemahan dari kata asing self-regulated learning. ${ }^{5}$ Sehingga regulasi diri berperan penting dalam proses belajar dan pembelajaran serta prestasi dan hasil belajar siswa yang optimal.

${ }^{1}$ Tria Agustina," Strategi Pengasuhan Remaja oleh Buruh Pabrik Wanita dalam Upaya Pencegahan Prilaku Menyimpang"

${ }^{2}$ Ibid,. 16.

${ }^{3}$ Novan Ardy, Wiyani, Konsep Dasar PAUD (Yogyakarta: Gava Media, 2016), 196.

${ }^{4}$ Lisya Chairani dan M.A. Subandi, Psikologi Santri Penghafal Al-Qur'an (Yogyakarta: Pustaka Pelajar, 2010), 14.

${ }^{5}$ Ruseno Arjanggi dan Titin Suprihatin, "Metode Pembelajaran Tutor Teman Sebaya Meningkatkan Hasil Belajar Regulasi Diri”, (Semarang: Jurnal Psikologi Islam Sultan Agung (Unissula), Vol. 14, No. 2, 2010), 92. 
Hasil belajar ialah kemampuan yang diperoleh anak setelah mengikuti kegiatan belajar. Belajar itu sendiri merupakan suatu proses dari seseorang yang berusaha untuk memperoleh suatu bentuk perubahan prilaku yang relatif menetap. Dalam proses pembelajaran yang terprogram dan terkontrol yang disebut kegiatan pembelajaran atau kegiatan instruksional, tujuan belajar telah ditetapkan lebih dahulu oleh guru.Anak yang berhasil dalam belajar ialah yang berhasil mencapai tujuan-tujuan pembelajaran atau tujuan-tujuan instruksional. ${ }^{6}$

Beberapa penelitian menunjukkan bahwa pola asuh yang diterapkan oleh orang tua berpengaruh terhadap hasil belajar siswa yaitu penelitian yang dilakukan oleh Ika Widhiasih yang berjudul "Pengaruh Pola Asuh Orang Tua Terhadap Hasil Belajar IPS " menunjukkan adanya pengaruh dan hubungan kuat antara pola asuh orang tua terhadap hasil belajar siswa. Dalam penelitian lain yaitu penelitian yang dilakukan oleh Fitrian Nur Febriary yang berjudul "Pengaruh Pola Asuh Orang Tua Terhadap Prestasi Belajar Siswa Pada Mata Pelajaran Ekonomi Di Sma Negeri 1 Parongpong Tahun Ajaran 2017/2018” terdapat pengaruh yang signifikan antara pola asuh orang tua terhadap prestasi belajar siswa. Sekolah Menengah Pertama Negeri 1 Balong merupakan lembaga pendidikan yang sudah berdiri sejak tahun 1983 dengan program pendidikannya dilaksanakan tiga tahun. Mata pelajaran IPS merupakan salah satu mata pelajaran yang harus ditempuh oleh kelas VII di Sekolah Menengah Pertama Negeri 1 Balong pada tiap semester.

Sekolah menegah pertama SMP bertujuan untuk mewujudkan dan menyiapkan siswa untuk memiliki kemampuan meneruskan jenjang pendidikan yang lebih tinggi yaitu SMA/SMK.Beberapa usaha untuk mewujudkan hal tersebut dengan meningkatkan hasil belajar yang baik. Hasil belajar dipengaruhi oleh beberapa faktor, yakni faktor internal (kesehatan, motivasi, regulasi diri, perhatian), sedangkan faktor eksternal meliputi (keluarga, sekolah, masyarakat).

Dari hasil observasi pengamatan langsung di lapangan pada magang 1 magang 2, bayak orang tua dari siswa tidak mendapingi siswa dalam belajar, karena banyak dari para orang tua sibuk bekerja di dalam dan luar negeri (TKI).Padahal yang diperlukan seorang anak ialah perhatian, dorongan, motivasi dan bimbingan dari orang tua, guru maupun hal tersebut bisa saja mucul di dalam dirinya sendiri.Sehingga siswa belajar hanya untuk memenuhi kewajiban atau tugas dari guru. Sebenarnya keberhasilan seorang siswa ditentukan dengan adanya dorongan belajar dari orang tua, dalam dirinya sendiri (regulasi diri), dan guru. Permasalahan yang dialami siswa kelas VII SMP 1 Balong adalah hasil belajarnya kurang maksimal. Dari uraian tersebut, penulis merasa tertarik untuk mengadakan penelitian pola asuh orang tua dengan judul "Pengaruh Pola Asuh Orang Tua Dengan Pendekatan Regulasi Diri Terhadap Hasil Belajar IPS Terpadu Siswa SMP”.

${ }^{6}$ Mulyono Abdurahman, Pendidikan Bagi Anak Berkesulitan Belajar (Jakarta: Rineka Cipta, 2003), 37-38. 


\section{METODE PENELITIAN}

Penelitian ini merupakan jenis penelitian kuantitatif. Penelitian kuantitatif memusatkan pada gejala-gejala yang mempunyai karakteristik tertentu di dalam kehidupan manusia yang disebut sebagai variabel. ${ }^{7}$

Variabel penelitian merupakan suatu atribut atau sifat atau nilai dari orang, objek, atau kegiatan yang mempunyai varisasi tertentu yang telah ditetapkan peneliti untuk dipelajari dan ditarik kesimpulannya. ${ }^{8}$ Varabel yang digunakan dalam penelitian ini yaitu:

1. Variabel Independen (variabel bebas) adalah variabel yang mempengaruhi atau yang menjadi sebab perubahan atau timbulnya variabel lain. ${ }^{9}$ Dalam penelitian ini variabel independen adalah Pola asuh orangtua di kelas VII (X).

2. Variabel dependen (variabel terikat) adalah variabel yang dipengaruhi atau menjadi akibat, karena adanya variabel lain. ${ }^{10}$ Variabel dependen dalam penelitian ini adalah hasil belajar siswa kelas VII (Y).

Teknik pengumpulan data adalah cara yang dapat digunakan oleh peneliti untuk mengumpulkan data. ${ }^{11}$ Adapun teknik pengumpulan data yang digunakan dalam penelitian ini yaitu dengan menggunakan angket dan dokumentasi. Untuk mengetahui pengaruh antara variabel $X$ (Pengaruh ppla asuh orang tua dengan pendekatan regulasi diri) dan variabel Y (Hasil belajar) maka, data akan dianalisis menggunakan analisis statistik diskriptif, yang artinya data yang diperoleh dalam penelitian ini disajikan apa adanya yang kemudian dianalisis secara diskriptif untuk mendapatkan gambaran mengenai fakta yang ada untuk menjawab permasalahan yang telah dirumuskan. Penelitian ini menggunakan analisis diskriptif dan kuantitatif.

\section{HASIL DAN PEMBAHASAN}

Untuk memperoleh data mengenai konsep diri siswa, peneliti mengunakan metode angket. Pada penelitian ini objek penelitiannya adalah siswa kelas VII di SMPN 1 Balong dengan jumlah 61 siswa.Dibawah ini merupakan deskripsi secara umum identitas dari responden pada penelitian.

1. Deskripsi Jenis Kelamin Responden

Mengacu pada hasil penelitian dan data yang dihasilkan dari sebaran angket, maka didapatkan data mengenai jenis kelamin responden pada gambar tabel di bawah ini:

Tabel 1. Jenis Kelamin Responden

\footnotetext{
${ }^{7}$ Deni Darmawan, Metode Penelitian Kuantitatif(Bandung: Remaja Rpsdakarya, 2014), 127128

${ }^{8}$ Ibid., 130

${ }^{9}$ Andhita Dessy Wulansari, Penelitian Pendidikan: Suatu Pendekatan Praktik dengan Menggunakan SPSS (Ponorogo: STAIN Po PRESS, 2012), 59

${ }^{10}$ Ibid.,59

${ }^{11}$ Wulansari, Penelitian Pendidikan: Suatu Pendekatan Praktik dengan Menggunakan SPSS, 64.
} 
JIIPSI: Jurnal Ilmiah Ilmu Pengetahuan Sosial Indonesia Nomor 1 Volume 1 Tahun 2021, hal 24-30

\begin{tabular}{|c|c|c|}
\hline Jenis Kelamin & Jumlah & Frekuensi \\
\hline Laki-Laki & 31 & $52 \%$ \\
\hline Perempuan & 30 & $48 \%$ \\
\hline Total & 61 & $100 \%$ \\
\hline
\end{tabular}

Pada tabel 1. di atas dapat diketahui bahwa responden terbanyak adalah laki-laki yaitu sebanyak 31 responden (51\%), sedangkan perempuan sebanyak 30 responden (47\%). Dengan demikian dapat diketahui secara umum bahwa siswa laki-laki lebih banyak daripada perempuan.

2. Data hasil belajar siswa diperoleh melalui nilai ujian akhir semester. Berikut merupakan nilai ujian akhir semester siswa kelas VII SMP N 1 Balong.

Untuk mengetahui hasil belajar siswa termasuk ke dalam kategori sangat baik, baik, cukup, kurang dan sangat kurang maka terdapat rumus seperti di bawah ini:

\begin{tabular}{|c|}
\hline Presentase $=$ \\
$\frac{\text { Frekuensi }}{\text { Jumlah siswa dalam } 1 \text { kelas }}$ \\
\hline
\end{tabular}

Tabel 1.2

Data hasil belajar IPS Terpadu

\begin{tabular}{|c|c|c|l|}
\hline Inversal & $\begin{array}{c}\text { Frekuensi/ Jumlah } \\
\text { siswa }\end{array}$ & kategori & \multicolumn{1}{|c|}{ Presentase } \\
\hline $81-100$ & 53 & Sangat baik & $86,88 \%$ \\
\hline $61-80$ & 7 & Baik & $11,48 \%$ \\
\hline $41-60$ & - & Cukup & - \\
\hline $21-40$ & 1 & Kurang & $1,64 \%$ \\
\hline $0-20$ & - & Sangat Kurang & - \\
\hline \multicolumn{2}{r}{ Total } & $100 \%$ \\
\hline
\end{tabular}

Pada tabel diatas dapat diketahui bahwa nilai ujian akhir semester genap siswa kelas VII SMPN 1 Balong yang termasuk kategori palingbaik dengan nilai 81-100 dengan frekuensi 82,88\% sebanyak 53 siswa. Selanjutnya yang termasuk kategori baik nilai 61-80 dengan frekuensi 11 dengan nilai 2140dengan frekuensi 1,64\% sebanyak 1 siswa.

Orang tua mempunyai peranan penting dalam mengasuh anak pada proses pendidikan dan pola asuh orang tua bisa mempengaruhi anak dalam mengelola bahkan mengendalikan diri. Dengan kata lain anak dapat meregulasi diri sendiri sebagai strategi yang berpengaruh terhadap performasi anak untuk mencapai tujuan atau prestasi sebagai bukti peningkatan hasil belajar. 
Hasil penelitian sesuai dengan pendapat Slameto yang mengungkapkan bahwa ada 2 sebab yang membuat prestasi belajar siswa, 2 sebab tersebut yakni interen dan eksternal. Pola asuh orang tua merupakan salah satu sebab eksternal. ${ }^{12}$

Sejalan dengan pernyataan tersebut, Beck menyatakan bahwasannya pengasuhan orangtua yang secara maksimal, digambarkan dengan orang tua bersikap peduli bisa mengetahui kebutuhan (psikologis, intelektual dan sosiokultural), maka hal tersebut akan membawa anak merasa nyaman dan integritas anak tersebut akan berkembang secara baik ketingkatan yang lebih tinggi. $^{13}$

\section{PENUTUP}

Berdasarkan hasil penelitian dan pembahasan dapat ditarik kesimpulan sesuai dengan perumusan masalah bahwa variabel pola asuh orangtua $(\mathrm{X})$ berpengaruh secara langsung maupun tidak langsung terhadap hasil belajar IPS terpadu (Y) dengan pendekatan regulasi diri $(Z)$. Hal ini dikarenakan orangtua memegang peranan yang sangat penting dalam hal pengasuhan anak dalam proses pendidikan, pola asuh orangtua dapat mempengaruhi anak dalam mengegelola diri sendiri. Dengan kata lain anak dapat meregulasi diri sendiri sebagai strategi yang berpengaruh terhadap performasi anak untuk mencapai tujuan atau prestasi sebagai bukti peningkatan hasil belajar. Hasil dan penelitian ini membuktikan bahwa variabel pola asuh orang tua $(\mathrm{X})$ menunjukkan bahwa pola asuh orang tua berpengaruh terhadap hasil belajar siswa pada mata pelajaran IPS Terpadu (Y) sebesar $25 \%$.

\section{DAFTAR PUSTAKA}

Abdurahman, Mulyono. Pendidikan Bagi Anak Berkesulitan Belajar. Jakarta: Rineka Cipta, 2003.

Agustina, Tria. Strategi Pengasuhan Remaja oleh Buruh Pabrik Wanita dalam Upaya Pencegahan Prilaku Menyimpang.

Arjanggi, Ruseno dan Titin Suprihatin. Metode Pembelajaran Tutor Teman Sebaya Meningkatkan Hasil Belajar Regulasi Diri. Semarang: Jurnal Psikologi Islam Sultan Agung (Unissula), Vol. 14, No. 2, 2010.

Chairani, Lisya dan M.A. Subandi. Psikologi Santri Penghafal Al-Qur'an. Yogyakarta: Pustaka Pelajar, 2010.

Darmawan, Deni. Metode Penelitian Kuantitatif. Bandung: Remaja Rosdakarya, 2014.

M. Fatih. Pengaruh Pola Asuh dan Self Efficacy terhadap Hasil Belajar IPA pada Siswa SDN Kepanjen Kidul 3 Kota Blitar. Malang: Skripsi UM, 2013.

12 Ika Widhiasih, Skripsi, "Pengaruh Pola Asuh Orang Tua Terhadap Hasil Belajar IPS Siswa Kelas IV SD Negeri Se-gugus Kresna Kecamatan Semarang Barat" (Semarang: UNNES, 2016), 189.

${ }^{13}$ M. Fatih, Skripsi, "Pengaruh Pola Asuh dan Self Efficacy terhadap Hasil Belajar IPA pada Siswa SDN Kepanjen Kidul 3 Kota Blitar" (Malang: UM, 2013), 131. 
JIIPSI: Jurnal Ilmiah Ilmu Pengetahuan Sosial Indonesia Nomor 1 Volume 1 Tahun 2021, hal 24-30

Novan Ardy, Wiyani. Konsep Dasar PAUD. Yogyakarta: Gava Media, 2016.

Widhiasih, Ika. Pengaruh Pola Asuh Orang Tua Terhadap Hasil Belajar IPS Siswa Kelas IV SD Negeri Se-gugus Kresna Kecamatan Semarang Barat. Semarang: Skripsi UNNES, 2016.

Wulansari, Andhita Dessy. Penelitian Pendidikan: Suatu Pendekatan Praktik dengan Menggunakan SPSS. Ponorogo: STAIN Po PRESS, 2012.

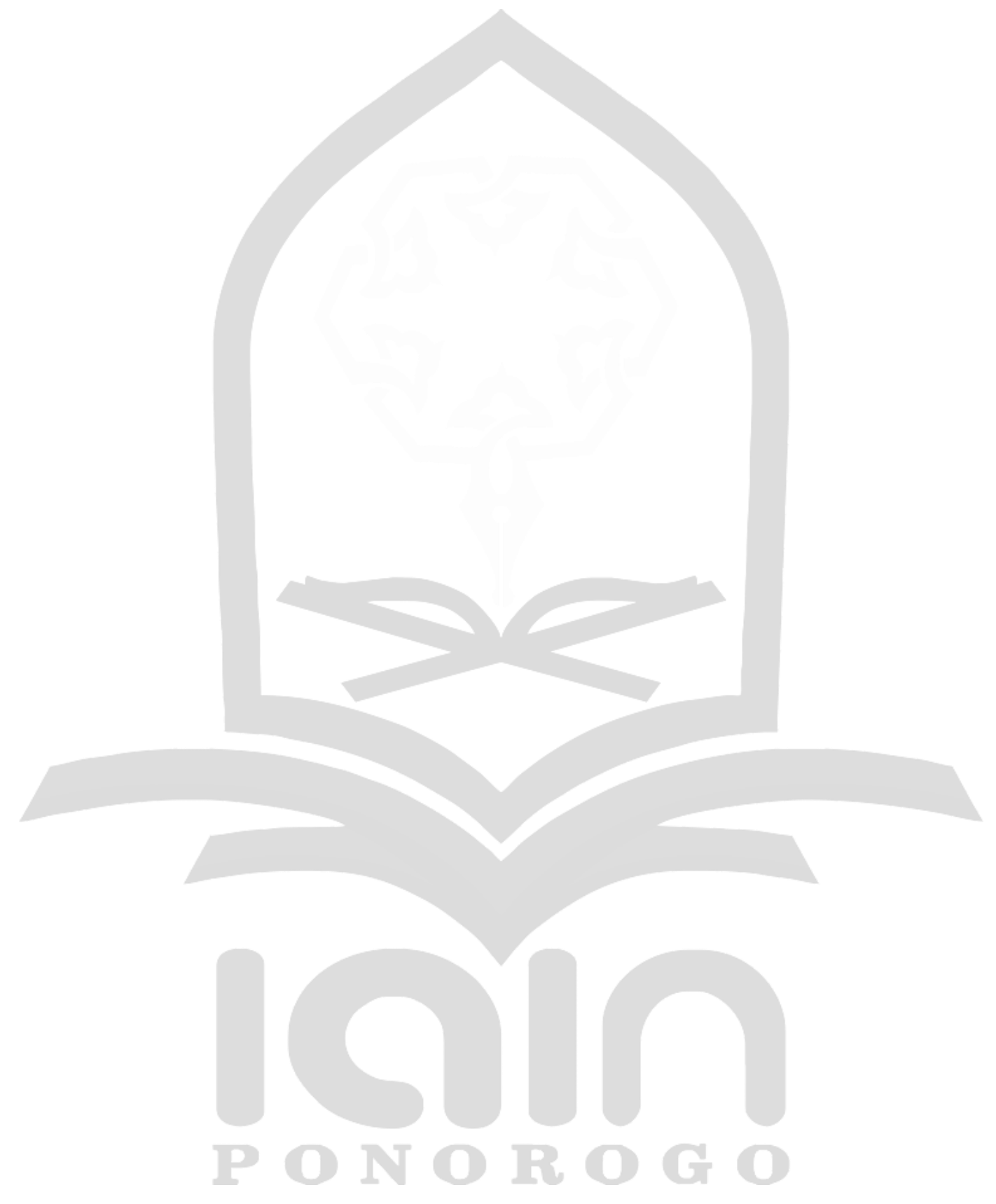

